\title{
Limits of the LMD Reform in Cameroon
}

\author{
Mounton Njoya Felix¹, Maba Kengne Stephanie Sophie ${ }^{2}$ \\ ${ }^{1}$ Zhejiang Normal University, Jinhua, China \\ ${ }^{2}$ Shanghai International Studies University, Shanghai, China \\ Email: mountonnjoyafelix@gmail.com,mabasophie@gmail.com
}

How to cite this paper: Felix, M. N., \& Sophie, M. K. S. (2022). Limits of the LMD Reform in Cameroon. Creative Education, 13, 617-626.

https://doi.org/10.4236/ce.2022.132038

Received: January 12, 2022

Accepted: February 19, 2022

Published: February 22, 2022

Copyright (C) 2022 by author(s) and Scientific Research Publishing Inc. This work is licensed under the Creative Commons Attribution International License (CC BY 4.0).

http://creativecommons.org/licenses/by/4.0/ (c) (i) Open Access

\begin{abstract}
For more than two decades, the LMD system has been gaining more and more ground in universities, especially those in Europe and Africa. It was introduced in Cameroon universities in 2007, and several years after its implementation, there is obviously a lack of real progress in the internationalization and globalization of higher education. This article aims at drawing the attention of the authorities in charge of higher education to the challenges facing higher education institutions under the LMD system and proposes some possible solutions that can help improve the situation on the field. As such, the paper focuses on a contextualized definition of the LMD system and its objectives as thought by its founders at the Bologna process in 1999, which lead to one of the questions asked by many authors but still to be answered till date, namely "The LMD reform in Cameroon: A reform for which objectives?". The next point is dedicated to some arguments that have encouraged the implementation of the LMD system in Cameroon as well as their limits. Finally, the paper proposes some solutions for the improvement of the LMD system if Cameroon intends to preserve this system for a long time. The main results that have evolved from the research are: the LMD system as applied in Cameroon universities doesn't match with the original objectives; the adoption of the LMD model appears to be premature in Cameroon; the Cameroonian university environment requires a lot of upgrading work before embracing and really benefiting from the LMD system.
\end{abstract}

\section{Keywords}

LMD System, Limits, Cameroon

\section{Introduction}

This research endeavor sets out to analyze the reform of higher education, known as "LMD" in Cameroon, from the angle of the limits of its implementa- 
tion. It comes as a response to one of the difficulties many Cameroonian youths face as soon as they graduate from high school and get admitted into their first year in university. Let's consider the following example: Yaoundé, the capital city of Cameroon, has two public universities, namely the University of Yaoundé I and the University of Yaoundé II. After the registration in the first year at the University of Yaoundé I, students are often asked to choose the courses they shall follow for the account of the first year. It should be noted that the subjects are classified into three categories, namely the fundamental teaching units, the complementary teaching units and the transversal teaching units. The fundamental and transversal teaching units have to be done on the main campus of the University of Yaoundé I, while students who have choose certain complementary teaching units should go to the campus of the University of Yaoundé II to follow these complementary teaching units.

However, for this particular group of students, a month later they were asked to change the subjects they had chosen for the complementary teaching units and to replace them with the subjects taught at the University of Yaoundé I because, according to the people in charge, the transfer of credits from the University of Yaoundé II to the University of Yaoundé I was and is still a long and complicated process.

This issue of non-transfer of teaching units' credits indeed is a paradox considering the fact that both universities are run with the norms of the LMD system, and this paradox constitutes the outset of the research.

In fact, since the adoption of the LMD system in Cameroon, its implementation has shown some flaws such as the one illustrated above, but also other issues such as students' mobility, professional integration of students after graduation etc. This question of the efficiency of the LMD system has triggered previous research from different angles and they are considered in the next session.

\section{State of the Art and Statement of the Problem}

From the outset, there is an abundant literature pertaining to the mutations, challenges and crises that higher education system has gone through in Cameroon.

Having explored some key researches, three main categories stood out.

The first category of authors aims at aligning Cameroon's higher education system to international standards. As such Gabriel NOUMEYI (2008), following the thought of Pr Paul Gerrard Pougoue suggested that, the purpose of the LMD system should aim above all to align Cameroonian higher education with international standards. This argument has also been highlighted by Yves Bertrand Djouda Feudjio (2009) who clearly supports in his work that the LMD system should aim at an academic globalization with the harmonization of academic systems, implying the respect of international standard.

In the second group, researchers are more interested in the promotional aspect of professionalization in order to solve the problem of unemployment among graduates. Innocent Fozing (2013), Marilyne Ngambo Tchofo (2021) both 
maintain that, under the LMD reform, there should be greater flexibility for academic training oriented towards research and training focused on professionalization. In his groundbreaking paper named "Le système LMD et la professionnalisation L'Expérience de la Facultés des lettres et sciences de l'Université de Dschang" ${ }^{\text {"S }}$ Charles-Robert DIMI also puts out some interesting arguments in favor of the professionalization of education in Cameroon.

Finally, we have the third group authors who are much more interested in the problem of students' mobility, the transferability of credits and the comparability of courses. All these authors deal with very important aspects for a good implementation of the LMD system in Cameroonian universities, but the fact of approaching them separately can prevent from seeing the gravity of the situation. In this category, some key research results include Nadine Ndjomo (2020), Bachir Bouba (2014). In her paper, Nadine Ndjomo upholds that, three key important elements of the LMD system, namely the facilitation of student mobility, transferability of credits and comparability of courses are still not effective within many university institutions in Cameroon fourteen years after the adoption of LMD reform.

It is obvious that challenges facing higher education in Cameroon have been researched and pointed out already. From the above review, it seems previous research are more concerned with three aspects of the LMD system. These aspects are only part of the whole of the reforms of the LMD. Also most of the authors are more concerned with the unemployment aspect rather than the quality of education.

In order to add up to what has already been done by other researchers, this paper responds to three main problems which are: 1) the misunderstanding of "LMD reform" by Cameroonian institutions 2) Is the LMD system in Cameroon implemented in accordance with resolutions of the Bologna process? 3) What could be done to improve on the LMD system if Cameroon intends to preserve this system for a long time?

\section{Methodology}

This paper not only focuses on documents analysis, but also combines personal observations as the second promotion to graduate under the LMD system at The University of Yaoundé I in Cameroon. Also, the arguments set out here as well as the solutions proposed for a better implementation and application of the LMD system are drawn from discussions of the researcher with some executives (4) and lecturers (7) of three public universities in Cameroon, in particular the University of Yaoundé I, the University of Yaoundé II and University of Douala who came for a mission at Zhejiang Normal University in 2018. At that time as a $\mathrm{Ph} . \mathrm{D}$. student at Zhejiang Normal University the researcher was chosen to guide them during their trip in China. Therefore, each time there was an opportunity to sit with different member of the delegation, the main topic of discussion was the LMD in Cameroon, features of both the old system and new system known 
as LMD, as well as their personal opinion and appreciation of the two systems.

\section{What Is the Original Meaning of the LMD System?}

The acronym L.M.D. means Licence (Bachelor's Degree), Master, Doctorate. These diplomas are converted into European credits that are called ECTS (European Credit Transfer System). These credits allow all students from any country and university to continue their studies at another European university.

\section{Objectives of the LMD System as thought by Its Founders}

As thought by its founders, the "LMD" system aims to harmonize higher education courses in Europe and to promote student mobility at regional, national and European levels.

Beside this main objective, there also specific objectives such as: the creation of flexible and efficient training paths, offering students, at all levels, opportunities for professional integration; promotion of students mobility nationally and internationally; facilitation of diplomas' equivalence; Creation of a new generation of versatile graduates able to adapt to a changing global context.

Finally, insure that for the all parties concerned (students, parents, professionals, employers, etc.) there is a better appraisal of the training grades and levels of professional integration.

Earlier after the implementation of the LMD system in Cameroonian Universities, some authors like Djouda Feudjio, B.Y. (2009) were already worried about the way decision makers were orienting things and deemed it necessary to remind to institutional leaders the main objectives of the LMD system. Unfortunately, many years after no actual changes can be witnessed on the field.

\section{The LMD Reform in Cameroon: A Reform for Which Objectives?}

The LMD system has been strung and packaged from the West and imported to Africa and more precisely to Cameroon with its advantages but also with its many disadvantages. What are the real aims of the LMD (Bachelor-MasterDoctorate) system in Cameroon? For Richard Atimniraye Nyéladé (2013), the imposition of this system in Africa in general is in line with a fatal program of instrumentalization and imperialism.

This system of evaluation of higher education was introduced during the academic year 2007-2008 in higher education institutions of Cameroon in replacement of the older diplomas of French origin namely the General University Diploma (DEUG), Maîtrise and Advance Diploma (DEA) which will later on disappeared from the landscape. Since the implementation in 2008 of the LMD system in universities in Cameroon, reservations have been voiced by some scholars on its efficiency and also on the lack of clarity of its objectives for Cameroonian universities. More than ten years after the LMD system has been implemented, one can still wonder if higher education institutions in Cameroon 
were ready for such a change. In other words, was the implementation of the LMD system into Cameroonian universities, at least as far as state-run universities are concerned, not hasty and therefore premature?

\section{Some Arguments that Have Encouraged the Implementation of the LMD System in Cameroon and Their Limits}

The defenders of the LMD project at the time of its introduction in Cameroon put forward its advantages and also the solutions that it was supposedly likely to bring to the problems facing Cameroonian universities. Their arguments were based on the following points:

\section{1) The old system was Obsolete}

According to some scholars, the system that prevailed before the introduction of the LMD system was obsolete. There was a huge gap between the content of the courses of different curricula and the current prevailing state of scientific research. The evaluation system that constituted a fundamental component of the educational system had lost all meaning. The multiple accommodations made by scholars to increase students' success rates had completely skewed the meaning of exams. To pass his various modules for example, the student did not need to work too much. The control of students' knowledge had become irrelevant. The old system was crumbling in the face of these inconsistencies and the diplomas issued were losing their value. Reforming it had become a necessity (according to the LMD defenders).

\section{- The Limit of the argument}

However, the LMD evaluation is supposed to integrate $70 \%$ of the student's personal work which in turn will empower him in his/her learning activity. This is supposed to improve the level of training and to revise the classical conception of education. But how will such a parameter be applicable in a university environment known for the poverty of its libraries and the lack of true multimedia centers. At the University of Dschang, for example, there are about 120,000 books in the central library, and newspapers and magazines that date back to the years before 2012. At the same time the Central library of Zhejiang Normal University (China) in 2015 had 3,500,000 books and over 2,300,000 e-books. This infrastructural gap already gives a glimpse of the quality of training that will be done here and there. Although all said to be under the LMD system. We are therefore, bound to conceive various degrees of the LMD system namely; a so-called "North" and so-called "Southern" LMD. This infrastructure problem is obviously not limited to libraries, since it also resurfaces when it comes to our laboratories for research. Then, the non-stable nature of our state universities do not prepares for the LMD either. In fact, it is rare to spend a year without attending a strike (teachers or students), which has the merit to paralyze the academic life; thereby weakening competitiveness of Cameroon Universities at the international level. 


\section{2) Difficult management of student flows}

The management of student flow is considered essential. Giving each high school graduate an opportunity to receive higher education has become an important issue for higher education officials in Cameroon. But, they realized that with the increasing number of graduates (which is on the verge to exceed one million); this principle was difficult to satisfy. The LMD, unlike the old system, offered stages in university training. Officials originally intended to put the majority of students on the job market after the undergraduate level; thereby reducing the number of students going for long-term studies.

\section{- The Limit of the argument}

Levels L (License/Bachelor) M (Master) and $\mathrm{D}(\mathrm{PhD})$ according to them should in principle help reverse the pyramid of graduates. Unlike the old system, the LMD provides for three levels, Bachelor, master and doctorate. Higher Education officials relied on this leveling organization to manage the large flow of students. In the old system the majority of students enrolled for long-term studies (5 years). The idea that students could leave the university after the undergraduate degree, acquired only in three years, is very attractive to those who think that the problems of the university come only from the growing number of students. This vision however, could not be realized. The students realized early on that they had no chance of entering the job market if they only stopped at undergraduate level. They therefore opted to study as long as possible and long term enrollment became their main demand. They have thus succeeded in defeating the application of the LMD reform as it was thought by its designers who had invented it in reference to countries whose economy generated jobs. This is not the case in our country. As a result, we clearly see that the primary objective of the LMD system which is: "one student, one job" is still a myth for young Cameroonian graduates.

3) LMD system: guaranty for more mobility of Cameroonian students to western universities.

The LMD was supposed to help Cameroonian universities open up to the world and particularly to the European Union by facilitating a greater mobility of Cameroonian students as same as European students who can more easily integrate other universities in the EU community. This objective was to be achieved by standardizing the management of the different curricula by introducing the concepts of credits and training courses. In principle, each student can build it training course and register to acquire the necessary credits. This is the foundation of the Bologna reform.

\section{- The Limit of the argument}

By adopting the same system of higher education as the European Union (EU), Cameroonian officials had seen an advantage in cooperative relations with these countries and particularly with France. But the reality of the situation reveals that, cooperation with the EU followed other criteria; the same that prevailed well before the introduction of the LMD. Universities in third world countries were still considered by developed countries as a reservoir from which 
they draw what may interest them (gifted African students) to strengthen their scientific potential. On the other hand, the lack of a national development policy that defines the role to be played and the place of the university in achieving these goals have helped this type of "dominant-dominated" cooperation. Still about the so-called openness to the world, the Cameroonian universities have made not much progress. It can also be noted that, the internal mobility of Cameroonian students instead of being encouraged has rather been limited. The diversity of training curricula in each university makes it difficult to achieve students' mobility. The difference between the courses of the same specialty is often huge.

\section{4) The problem of qualification for $\mathrm{PhD}$}

At the end of the Master cycle, students can apply to prepare a $\mathrm{PhD}$. All students holding a Master's degree can apply for a doctoral dissertation, be it an academic master's degree or a professional master's degree. The duration of doctoral preparation is generally three years (it corresponds to a diploma BAC + 8 years of study). The different training courses proposed must be in line with the needs of the job market, supposedly.

\section{- The Limit of the argument}

Unfortunately, Cameroon does not apply the LMD as thought by its founders since the beginning because today, there are ongoing debates stating that the professional doctorate would be worth less or not equal to the academic doctorate; while the LMD system has not categorized the doctorate. Added to this is the blockade inflicted by the elders to the young doctoral students of Cameroon. The LMD envisages 3 years of research and writing, but the observation on the ground reveals that the lucky ones defend their thesis after 5 years.

\section{What Could Be Done If Cameroun Intends to Preserve This System for a Long Time?}

\section{1) At the institutional level}

As long as certain problems have not been solved, it is illusory to claim effective implementation of the LMD system. Its effective application depends on a certain stability of the university environment, needless to mention here the lack of sanitary infrastructures or the general insalubrity of the classrooms.

The competitiveness of the universities implied by globalization places at the heart of the concerns the need to revise upward the budgetary allocations granted to state universities and their fair distribution. For a true application of the LMD system, it is necessary beforehand that the infrastructural and professional breaches mentioned above be plugged. Cameroon's state universities are therefore more of victims of a sudden adoption of the LMD system. For Djouda Feudjio, B.Y. (2009), the reform of the educational system in Cameroon should be based on the realities of Cameroon. The LMD is actually a pure imitation, a poorly designed copy of the system in Western universities. However, it is still time to rectify the situation, in particular by investing twice as much and rationally into the construction of laboratories, and the acquisition of books. 


\section{2) At students Level}

It is also important to invite students to be more responsible and careful about their learning environment. In other words, after the government has taken its responsibility by constructing some equipment like libraries, laboratories, toilets etc. Students should try and show some respect by keeping them safe and clean.

\section{3) Further discussion and suggestions}

It is worth remembering that, whatever efforts Cameroon may make for the financing of scientific research, if the training of future researchers is not of good standard then the investment will be a pure loss. It is obvious that, the university has a role to play in the development of the society. This conviction however is not always really shared by the leaders of the country, even if often it is reminded in official speeches.

To efficiently implement a policy like the LMD, the university community needs to work together to succeed in this task without which no development is possible. Scientific research in Cameroon can really fulfill its objectives only if it is part of the economic and industrial development process. Only a dynamic public sector is capable of leading such an orientation. Quality training is a necessary condition for useful scientific research in the broadest sense of the term. This link is often omitted in evaluating the performance of scientific research. This must be taken into account to avoid unnecessary expenses in projects that never succeed.

The number of students who enroll in universities each year is often considered the source of all problems in our Universities whereas, it is actually a major asset. This can only be seen, if students graduate from high school with good grades. The real problem is therefore not the large number of students involved in higher education, but it is their mediocre level. Rigor in the application of the evaluation system is a necessity.

Mechanisms need to be found to mobilize teachers around this goal. Feudjio (2009) enlighten in few words those problems of implementation of the LMD in Cameroon when he says: "higher educational institutions are overcrowded, understaffed, poorly equipped and often decrepit, with poor student living and learning conditions. Furthermore, academic mobility is a concern still to be solved." In other words; there is an incompatibility between the current state of Cameroonian universities and their ability to adopt the Bologna Process. Their crises and dysfunctional mechanism militate against an effective implementation of the LMD system. Therefore, according to Daniel Franck Idiata (décembre 2012), much remains to be done to succeed in the large LMD project in African universities. Above all, African leaders have to consider the fact that the learning environment has a great impact on learners' mind.

\section{Conclusion}

This paper aimed at exploring the challenges to the implementation of the LMD system in Cameroon Universities, to analyze them in order to determine the best tracks and solutions for a better implementation of this reform in Cameroonian 
university institutions. Having explored different aspects of the issue, results reveal that the LMD system as applied in Cameroon universities doesn't match with the original objectives; the adoption of the LMD model appears to be premature in Cameroon; and also that, the Cameroonian university environment requires a lot of upgrading work before embracing and really benefiting from the LMD system. It was also found that less is said about the financial aspect of the reform. Therefore, to further this idea, future research could focus on that particular aspect.

\section{Conflicts of Interest}

The authors declare no conflicts of interest regarding the publication of this paper.

\section{References}

Bouba, B. (2014). De la théorie à la pratique: L'évaluation de la mise en œuvre du système LMD à l'Université de Maroua et la qualité de la formation [From Theory to Practice: Evaluation of the Implementation of the LMD System at the University of Maroua and the Quality of Training]. Revue de l'Association Francophone Internationale de Recherche Scientifique en Education, No. 11, 32-47.

Charles-Robert, D. (2014). Le système LMD et la professionnalisation l'expérience de la Facultés des lettres et sciences de l'Université de Dschang [The LMD System and Professionalization. The Experience of the Faculty of Letters and Sciences of the University of Dschang]. Colloque International.

Djouda Feudjio, B. Y. (2009). L'adoption du “système LMD” par les universités du Cameroun: Enjeux, contraintes et perspectives [The Adoption of the "LMD System" by the Universities of Cameroon: Challenges, Constraints and Prospects]. JHEA/RESA, 7, 141-157.

Fozing, I. (2013). L'enseignement supérieur à l'ère de la professionnalisation: Quel niveau de connaissance du système LMD chez des conseillers d'orientation des universités Yaoundé I et II [Higher Education in the Era of Professionalization: What Level of Knowledge of the LMD System among Guidance Counselors of Yaoundé I and II Universities]. Revue de l'Association Francophone Internationale de Recherche Scientifique en Éducation, No. 9, 31-52.

Idiata, D. F. (2012). Afrique dans le système LMD (Licence-Master-Doctorat). L'Harmattan, $296 \mathrm{p}$.

Lehman, L. G. (2008). Le Système LMD en question. Cameroun: Enseignement Supérieur.

Ndjomo, N. (2020). L'échec du système LMD. (The Failure of the LMD System). Sukulu News.

Noumeyi, G. (2008). Comment accompagner "le passage au système LMD” en vigueur dans quelques universités camerounaises [How to Support "the Transition to the LMD System" in Some Cameroonian Universities]. Le Messager.

Nyéladé, R. A. (2013). Le Système LMD une instrumentalisation occidentale? Harmattan Cameroun, $66 \mathrm{p}$.

Poeghela, C. K. (2011). Où en seront les bibliothèques camerounaises dans dix ans ? Bulletin des Bibliothèques de France (BBF), No. 6, 48-52.

Tchofo, M. N. (2021). Formation et Insertion Professionnelle: Ce Que Peuvent Les Universités d'Etat [Vocational Training and Integration: What State Universities Can Do]. Cameroon Business Today. 


\section{List of Abbreviations and Acronyms}

LMD License (often called Bachelor) -Master-Doctorate

ECTS European Credit Transfer System

ICTs Information and Communications Technology

$\mathrm{PhD} \quad$ "Doctor of Philosophy," commonly called a doctoral degree

DEUG General University Diploma

DEA Advance Diploma

EU European Union

BAC Baccalauréat, often known in France colloquially as bac, is an academic qualification that French students take after high school. 